\title{
Quality of Nutrition of Elderly with Different Degrees of Dependency: Elderly Living in Private Homes
}

\author{
Katharina Fritz Ibrahim Elmadfa \\ Department of Nutritional Sciences, University of Vienna, Vienna, Austria
}

\section{Key Words}

Elderly $\cdot$ Austrian nutrition $\cdot$ Nutrient intake

\begin{abstract}
Background/Aim: To be aware of the influencing factors of healthy aging, several cross-sectional surveys have been carried out among the elderly living in Austria to identify health and lifestyle factors as well as socioeconomic influences that contribute to the nutritional situation. Methods: Information about the health situation was collected by questionnaires. Diet was assessed by both qualitative food frequency questionnaires and 24-hour recalls. Additionally, nutritional status was examined in blood and urine samples using static and functional parameters. Results: The prevalence of overweight $(21 \%, \mathrm{BMI}>29)$ and obesity increased with increasing age up to 65 years; in people older than 65 years an inverse tendency could be observed; as from this age upwards a high prevalence of underweight was found $(22 \%$, $\mathrm{BMI}<24)$. The consumption of meat and meat products was too high compared to the recommendations. By contrast, the intake of high nutrient density foods was insufficient. On average, the fat intake was around $38 \%$ of total energy (\%E);
\end{abstract}

that of saturated fatty acids amounted to $20 \% \mathrm{E}$; the intake of carbohydrate and fiber was considered as being too low. The intake of folate, vitamin $D$, calcium, iodine, magnesium and vitamin $C$ was assessed as inadequate. Conclusion: More attention has to be paid to certain micronutrients in order to optimize dietary intake and to sustain health.

Copyright $\odot 2008$ S. Karger AG, Basel

\section{Introduction}

Nowadays, more and more elderly people become aware of their own health. The behavior or attitude towards life clearly influences a person's state of health [1]. Nutritional status as well as health status is, among other things, influenced by physiological, psychological, social, and situational factors.

In 1998, the nutritional situation in Austria was documented for the first time in the Austrian Nutrition Report 1998. The Institute of Nutritional Sciences collected data relating to diet, nutrition and lifestyle in selected population groups. In that survey only data on elderly living in nursing homes $(\mathrm{NH})$ were assessed. The nutrition

\section{KARGER \\ Fax +4161306 1234 E-Mail karger@karger.ch} www.karger.com

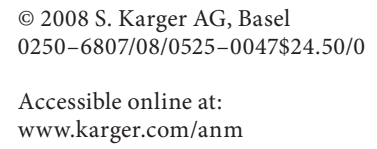

Katharina Fritz

University of Vienna, Department of Nutritional Sciences

Althanstrasse 14

AT-1090 Wien (Austria)

Tel. +43 14277549 51, Fax +4314277 9549, E-Mail katharina.fritz@univie.ac.at 
Fig. 1. Average intake of some micronutrients assessed as inadequate in the Viennese elderly $(n=645)$.

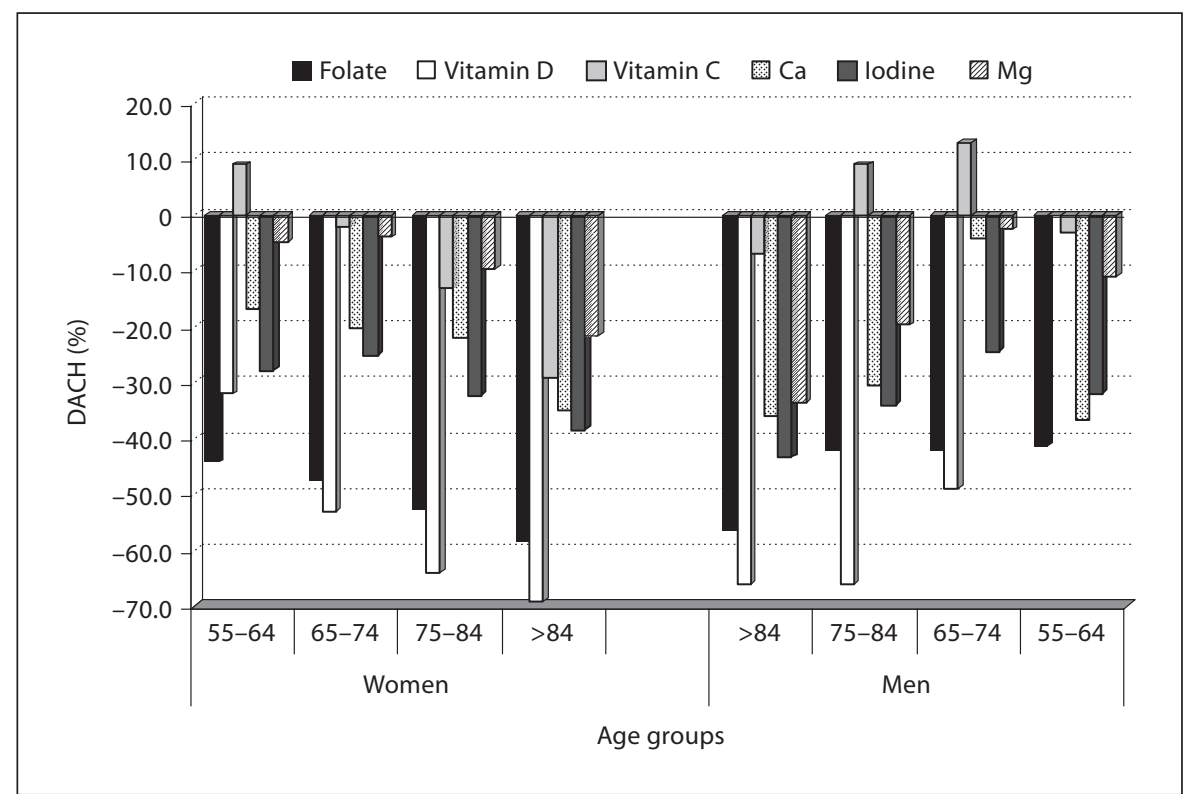

monitoring was continued with the Austrian Nutrition Report 2003, where for the first time elderly people living in private households $(\mathrm{PH})$ have been taken into consideration [2].

\section{Methods}

In the Austrian Study on Nutritional Status (ASNS) in 2003 both elderly people ( $>55$ years; $n=645$ : 557 women, 88 men) living in nursing homes $(\mathrm{n}=233)$ and in private households $(\mathrm{n}=410)$ were examined. Several methods of data collection were used to investigate health and lifestyle factors as well as diet, nutrition and nutritional behavior; these included a questionnaire, a qualitative food frequency questionnaire, a single 24-hour recall, and blood and urine samples.

Analyses of data in the elderly were done separately for gender, different age groups, and according to the living situation. For differences in energy and nutrient intake between $\mathrm{NH}$ and $\mathrm{PH}$, only people older than 65 years $(n=441)$ were considered.

Detailed information on the results has been documented in the Austrian Nutrition Report 2003 [1] and the Second Viennese Nutrition Report 2004 [3].

\section{Results}

The prevalence of overweight $(21 \%, \mathrm{BMI}>29)$ [4] and obesity rose with increasing age up to 65 years, whereas in people older than 65 years an inverse tendency could be observed. As from this age upwards a high prevalence of underweight was found $(22 \%, \mathrm{BMI}<24)$. The average $\mathrm{BMI}$ of the whole sample was $26.7 \pm 4.1$ within the range of normal weight. Overall, the majority of the sample (57\%) was in the normal range of the National Research Council (NRC). According to the living situation, no statistical differences in BMI were found. However, between the age groups the prevalence of underweight was in the 84 -year-olds 3 times higher than in the age group of the 55- to 64-year-olds. In general, the body weight tends to decrease with increasing age in healthy people [5].

The highest energy intake was found among men between the ages of 55 and 64 years $(9 \pm 3.2 \mathrm{MJ})$. Nevertheless, the average energy intake in every age group was below the recommendations of the D-A-C-H association [6]. The average protein intake in the elderly was, in relation to the total energy intake with $15 \% \mathrm{E}$, on the upper limit of the recommendations. In contrast, the fat intake on average was around $38 \% \mathrm{E}$. Fat is still a critical nutrient in the Austrian diet with regard to the level of intake and its fatty acid composition. The intake of saturated fatty acid (SFA) was considered to be too high $(18-20 \% \mathrm{E})$ on account of polyunsaturated fatty acids $(5 \% \mathrm{E})$. The intake of carbohydrates $(45 \% \mathrm{E})$ as well as of fiber $(20 \mathrm{~g} /$ day) did not meet the recommendations.

The average intake of some micronutrients was assessed as inadequate and therefore had to be considered as critical nutrients in the diet of the elderly (fig. 1) as follows: folate, vitamin $\mathrm{D}$, calcium, iodine, magnesium and vitamin $\mathrm{C}$ in people older than 84 years. 
Table 1. Mean daily intake of energy and macronutrients in Viennese seniors, separated by gender and age groups $(n=645)$

\begin{tabular}{|c|c|c|c|c|c|c|}
\hline & Total & 55-64 years & 65-74 years & $75-84$ years & $>84$ years & $\mathrm{DACH}$ \\
\hline \multicolumn{7}{|l|}{ Women $(n=557)$} \\
\hline Energy, MJ & $7.4 \pm 2.1$ & $7.5 \pm 2.3$ & $7.5 \pm 2.0$ & $7.4 \pm 1.9$ & $7.1 \pm 2.0$ & $8.5 / 7.5^{1}$ \\
\hline$\%$ E protein & $16 \pm 4$ & $16 \pm 4$ & $16 \pm 5$ & $16 \pm 5$ & $16 \pm 4$ & $10-15$ \\
\hline$\%$ E carbohydrates & $46 \pm 9$ & $47 \pm 9$ & $46 \pm 8$ & $45 \pm 9$ & $43 \pm 9$ & $>50$ \\
\hline Thereof sucrose & $9 \pm 5$ & $9 \pm 5$ & $9 \pm 5$ & $9 \pm 5$ & $9 \pm 5$ & - \\
\hline Fiber, $g$ & $19 \pm 7$ & $21 \pm 8$ & $20 \pm 7$ & $18 \pm 7$ & $16 \pm 6$ & $>30$ \\
\hline$\%$ E fat & $37 \pm 8$ & $36 \pm 9$ & $37 \pm 7$ & $38 \pm 8$ & $40 \pm 8$ & $30-35$ \\
\hline Thereof SFA & $18 \pm 3$ & $17 \pm 4$ & $17 \pm 3$ & $19 \pm 4$ & $20 \pm 3$ & $\max .10$ \\
\hline Thereof MFA & $14 \pm 2$ & $14 \pm 3$ & $14 \pm 2$ & $14 \pm 2$ & $15 \pm 2$ & 13 \\
\hline Thereof PFA & $5 \pm 3$ & $5 \pm 3$ & $6 \pm 2$ & $5 \pm 2$ & $5 \pm 2$ & 7 \\
\hline$\%$ E alcohol & $1.2 \pm 2.9$ & $1.4 \pm 4.0$ & $1.2 \pm 2.2$ & $0.8 \pm 1.9$ & $0.8 \pm 2.1$ & - \\
\hline \multicolumn{7}{|l|}{$\operatorname{Men}(n=88)$} \\
\hline Energy, MJ & $8.4 \pm 2.6$ & $9.0 \pm 3.2$ & $8.7 \pm 2.3$ & $8.7 \pm 2.3$ & $7.4 \pm 2.4$ & $10.5 / 9.5^{2}$ \\
\hline$\% \mathrm{E}$ protein & $15 \pm 5$ & $16 \pm 5$ & $16 \pm 5$ & $16 \pm 4$ & $14 \pm 5$ & $10-15$ \\
\hline$\% \mathrm{E}$ carbohydrates & $44 \pm 9$ & $45 \pm 9$ & $46 \pm 10$ & $42 \pm 6$ & $44 \pm 11$ & $>50$ \\
\hline Thereof sucrose & $9 \pm 8$ & $8 \pm 5$ & $8 \pm 4$ & $7 \pm 3$ & $11 \pm 15$ & - \\
\hline Fiber, $g$ & $20 \pm 8$ & $20 \pm 7$ & $23 \pm 9$ & $22 \pm 9$ & $15 \pm 5$ & $>30$ \\
\hline$\%$ E fat & $38 \pm 7$ & $36 \pm 6$ & $36 \pm 7$ & $40 \pm 6$ & $40 \pm 8$ & $30-35$ \\
\hline Thereof SFA & $18 \pm 3$ & $16 \pm 2$ & $17 \pm 3$ & $20 \pm 3$ & $20 \pm 3$ & $\max .10$ \\
\hline Thereof MFA & $15 \pm 2$ & $15 \pm 2$ & $14 \pm 2$ & $15 \pm 2$ & $15 \pm 2$ & 13 \\
\hline Thereof PFA & $5 \pm 2$ & $5 \pm 2$ & $5 \pm 2$ & $5 \pm 2$ & $5 \pm 2$ & 7 \\
\hline \%E Alcohol & $2.6 \pm 3.8$ & $3.4 \pm 4.9$ & $2.0 \pm 3.6$ & $2.3 \pm 2.6$ & $2.0 \pm 3.3$ & - \\
\hline
\end{tabular}

$\% \mathrm{E}=\%$ of total energy; $\mathrm{SFA}=$ saturated fatty acid; $\mathrm{MFA}=$ monounsaturated fatty acid; PFA = polyunsaturated fatty acid.

${ }^{1} 7.5 \mathrm{MJ} /$ day applies to women aged 65+ with a BMI in the normal range and PAL of 1.6.

$29.5 \mathrm{MJ} /$ day applies to men aged 65+ with a BMI in the normal range and PAL of 1.6 [6].

Generally, elderly living at home are better provided with macro- and micronutrients than elderly living in nursing homes. Seniors in PH consumed statistically significantly more fiber and carbohydrates $(\mathrm{p}<0.05)$ than people living in $\mathrm{NH}$, whereas the average intake of protein was significantly lower $(\mathrm{p}<0.05)$ in people living in $\mathrm{PH}$ (table 1). The supply of micronutrients of older selfindependent men is significantly higher $(\mathrm{p}<0.05)$ than the supply of their contemporaries in the nursing homes. Furthermore, the intake of total water was significantly higher $(\mathrm{p}<0.05)$ in people living in $\mathrm{PH}$. Again among self-dependent elderly, the vitamin $\mathrm{D}$ status was significantly higher $(p<0.05)$. These discovered differences have to be interpreted carefully because of both the low sample size, particularly in men $(n=65)$, and the method of data collection (24-hour recall).

Analyses on food consumption patterns showed that the intake of high nutrient density foods was mainly insufficient (e.g. vegetables, bread and cereals, milk and milk products), whereas the supply of meat and meat products, sugar and fats was too high according to the recommendations [7].

\section{Conclusion}

An adequate and balanced diet has a positive influence on the health-promoting lifestyle. As the results show, more attention has to be paid to certain micronutrients in the diet of elderly in order to optimize dietary intake and sustain healthiness.

\section{Disclosure Statement}

This study was financially supported by the 'Kuratorium Wiener Pensionisten-Wohnhäuser' (Board of Trustees Nursing Homes of Vienna), 'Lebensmitteluntersuchungsanstalt der Stadt Wien' (Food Control Institute of the Municipality of Vienna), and 'Gesundheitswesen und Soziales der Stadt Wien' (Health and Social Services of the Municipality of Vienna). 


\section{References}

1 Freidl W, Stronegger WJ, Neuhold $\mathrm{CH}$, Braunitzer V, Stift L, Csitkovics M, Amanshauser B, Bachinger E: Vienna Health and Social Survey. Vienna Health Reporting, 2001.

2 Elmadfa I, Freisling H, König J, Blachfelner J, Cvitkovich-Steiner H, Genser D, Grossgut R, Hassan-Hauser CH, Kichler R, Kunze M, Majchrzak D, Manafi M, Rust P, Schindler K, Vojir F, Wallner S, Zilberszac A: Austrian Nutrition Report 2003, ed 1. Vienna, Institute of Nutritional Sciences, University of Vienna, 2003.
3 Elmadfa I, Blachfelner J, Freisling H, Haas K, Rust P, Weichselbaum E: 2. Wiener Ernährungsbericht. Institute of Nutritional Sciences, ed 2. Vienna, University of Vienna, 2005.

4 National Research Council of the USA: Diet and Health: Implication for Reducing Chronic Disease. Washington, National Academic Press, 1989.
5 Bates CJ, Benton D, Biesalski HK, Staehelin $\mathrm{HB}$, von Staveren J, Stehle P, Suter PM, Wolfram G: Hohenheimer Konsensusgespräch - Ernährung und Altern. Aktuel Ernaehr Med 2001;26:285-302.

6 German Association for Nutrition (DGE), Austrian Association for Nutrition (OEGE), Swiss Association for Nutritional Research (SGE), Swiss Association for Nutrition (SVE): DACH Reference Values for Nutrient Intake, ed 1. Frankfurt am Main, Umschau Braus, 2000.

7 Deutsche Gesellschaft für Ernährung: Vollwertig essen und trinken nach den 10 Regeln der DGE. AID-Vertrieb DVG, 2001 